\title{
BIODIESEL FROM MICROALGAE: THE EFFECT OF FUEL PROPERTIES ON POLLUTANT EMISSIONS
}

\author{
J. C. L. Torrens ${ }^{\mathrm{a}}$, \\ J. V. C. Vargas ${ }^{a}$, \\ E. C. Telles ${ }^{\mathrm{a}}$, \\ A. B. Mariano ${ }^{a}$, \\ and J. C. Ordonez \\ ${ }^{\mathrm{a}}$ Universidade Federal do Paran \\ Departamento de Engenharia Mecânica \\ Bairro Jardim das Américas \\ CP. 19011, Curitiba, Paraná, Brasil \\ jonastorrens@gmail.com \\ jvargas@demec.ufpr.br \\ eniotelles@yahoo.com.br \\ andrebmariano@gmail.com \\ ${ }^{\mathrm{b}}$ Florida State University \\ Department of Mechanical Engineering and \\ Center for Advanced Power Systems \\ Tallahassee, Florida, 32310, USA
}

ABSTRACT

Recently, biofuels have been presented as a viable alternative for the main challenges of the energy industry: the depleting supplies of petroleum and the global warming due to greenhouse effect. Biofuels may be produced from several different feedstocks, such as sugarcane, animal fat, oil crops or even microalgae. Replacing conventional petroleum sourced fuels with biofuels may significantly reduce global greenhouse effect gases emission when considering the life cycle of such fuels. Even with this advantage, biofuels present new challenges concerning the engine adaptation and the pollutant emissions. In this context, this paper aims to clarify the relation between fuel properties of microalgae biodiesel and pollutant emissions, studying which properties are desirable in these new fuels to guarantee engine operation without degradation of performance in comparison to conventional diesel.

Keywords: Biodiesel; Microalgae; Fuel properties; Emissions

\section{INTRODUCTION}

In late years, many alternatives for conventional fuels have received increasing attention of both the scientific community and society. New alternatives for petroleum derived fuels are needed mainly because of petroleum depletion, since petroleum is not a renewable source, and because of global warming, which is caused by increasing atmospheric concentration of green house effect gases (mainly $\mathrm{CO}_{2}$ ).

Among the alternative fuels that have been studied, biofuels, derived from biomass, are been specially considered. Biodiesel, which is a fuel for compression ignitions engines (CI), is presented as a good alternative for conventional diesel fuels. Biodiesel can be defined as the mixture of fatty acids mono-alkyl esters (Dzida, 2007, and Knothe, 2005), which are normally obtained from vegetable oil or animal fats. In late years, oleaginous microorganisms (microalgae, yeast, fungi and bacteria) have also been considered as possible sources for biodiesel production (Chisti, 2007, Meng et al., 2009, Song, 2008).

In order to substitute conventional diesel, fuel properties of biodiesel must guarantee performances competitive with conventional diesel. As many authors have shown, biodiesel fuel properties are directly affected by the composition and by the neat fatty acid ester properties. Thus, the usage of a new feedstock such as microalgae for biodiesel production leads to the necessity of predicting fuel properties to detect possible problems concerning the fuel performance.

Recently pollutant emissions have received great attention, and the challenge of limiting such emissions has become one of the major issues of engine development. These emissions are affected by three main factors: the constructive aspects of the engine; the operational parameters and fuel properties. While using a new fuel, with different fuel properties, it is necessary to define what the effect on the emissions.

Fatty acid esters (FAE) molecules have oxygen, a desirable characteristic for a CI fuel. Literature agree that, operating on biodiesel, important reductions on carbon monoxide (CO), unburned hydrocarbons ( $\mathrm{HC}$ ) and particulate matter (PM) emission can be expected (Grabosky, 1998, Lapuerta et al., 2008). Most studies have reported a small increase on nitrogen oxides $\left(\mathrm{NO}_{\mathrm{x}}\right)$ while using biodiesel; doe, these results vary greatly, depending on the engine technology and the test procedure. Most of studies consider only the addition of biodiesel to conventional diesel, up to $20 \%$. However, the greatest potential of reduction on $\mathrm{CO}_{2}$ emissions may only be achieved with higher percentages of biodiesel or even the neat form of it. Thus, this work deals with neat biodiesel.

Many methods have been proposed to predict the physical and chemical properties of the neat FAE. 
Knowing the properties of the individual FAE, with a given composition, it's then possible to use mixing rules to estimate the properties of the fuel. The use of such methods a priori, based on the composition of the oil or fat, may help choosing the best feedstock for biodiesel production, avoiding expensive experimental procedures in the early phases of the fuel production investigation or even losses with the production of improper biodiesel.

Most studies concentrate on the biodiesel produced with methanol, resulting in fatty acid methyl esters (FAME), because methanol is the less expensive alcohol in most countries. However, specifically in Brazil, ethanol is less expensive, and therefore fatty acid ethyl esters (FAEE) are more interesting for biodiesel production in this country. The present work will then concentrate on FAEE, even if the methods presented are general enough to be used with FAME as well.

\section{BIODIESEL COMPOSITION}

Biodiesel can be produced from fats and oils by a reaction called transesterification. Most oils found in nature are mainly composed of triacylglycerols (also known as triglycerides), which are fatty acid ester of glycerol. In the transesterification reaction, these triesters are converted in mono-alkyl esters, as show in Fig.1. For biodiesel production, this reaction occurs in the presence of monohydric alcohol (such as methanol or ethanol), using an acid or basic catalyst, and produces glycerol as a byproduct (Grabosky, 1998). The reaction does not change the fatty acid profile of the oil, and so, this profile remains determinant on the fuel composition.

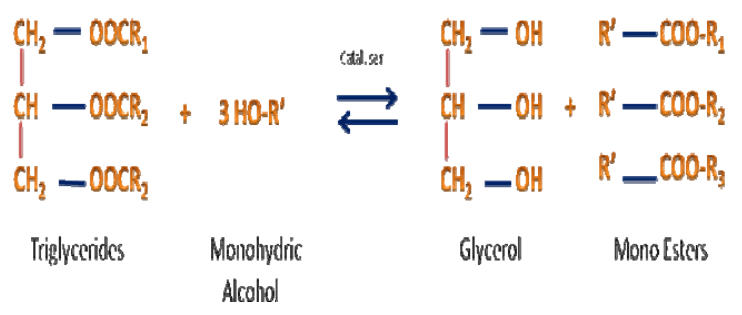

Figure 1. Transesterification of triglycerides

Recently, Knothe (2005) stated that the nature of the fuel components ultimately determines the fuel properties, even if these properties are influenced by contaminants from production process. In the case of biodiesel, both the oil and the alcohol used in transesterification affect the final product properties, and each ester component contributes to the properties of the fuel. Among the properties of biodiesel that are determined by the structure of the fatty ester the present work discusses the density, viscosity, vapor pressure, cold flow properties and ignition quality.
The composition of biodiesel varies depending on the feedstock. Each organism produces different triglycerides with different amounts and combinations of fatty acids. The most common fatty acids are those that posses 12 to 18 atoms of carbon. Some microorganisms may produce long chains containing up to 24 carbon atoms. These chains may be saturated or unsaturated, the latter having great impact on the fuel properties. Table 1 contains the most important fatty acids for fuel production and their structure.

Table 1.Basic properties of the most commonly found fatty acid ethyl esters needed for the estimations.

\begin{tabular}{|c|c|c|c|}
\hline $\begin{array}{c}\text { Shorthand } \\
\text { name }\end{array}$ & $\begin{array}{c}\text { Fatty acid } \\
\text { name }\end{array}$ & $\begin{array}{c}\text { Carbon } \\
\text { Number } \\
\text { of fatty } \\
\text { acid }\end{array}$ & Structure ${ }^{(1)}$ \\
\hline $\mathrm{C} 12: 0$ & Lauric & 12 & $\mathrm{CH}_{3}\left(\mathrm{CH}_{2}\right)_{10} \mathrm{COOH}$ \\
\hline $\mathrm{C} 14: 0$ & Myrisitc & 14 & $\mathrm{CH}_{3}\left(\mathrm{CH}_{2}\right)_{12} \mathrm{COOH}$ \\
\hline $\mathrm{C} 16: 0$ & Palmitic & 16 & $\mathrm{CH}_{3}\left(\mathrm{CH}_{2}\right)_{14} \mathrm{COOH}$ \\
\hline $\mathrm{C} 18: 0$ & Stearic & 18 & $\mathrm{CH}_{3}\left(\mathrm{CH}_{2}\right)_{16} \mathrm{COOH}$ \\
\hline $\mathrm{C} 16: 1$ & Palmitoleic & 16 & $\begin{array}{c}\mathrm{CH}_{3} \\
\left(\mathrm{CH}_{2}\right)_{5} \mathrm{CH}=\mathrm{CH}_{\left(\mathrm{CH}_{2}\right)_{7} \mathrm{COOH}}\end{array}$ \\
\hline $\mathrm{C} 18: 1$ & Oleic & 18 & $\begin{array}{c}\mathrm{CH}_{3} \\
\left.\left(\mathrm{CH}_{2}\right)_{7} \mathrm{CH}=\mathrm{CH}_{(\mathrm{CH}}\right)_{7} \mathrm{COOH}\end{array}$ \\
\hline $\mathrm{C} 18: 2$ & Linoleic & 18 & $\begin{array}{r}\mathrm{CH}_{3} \\
\left(\mathrm{CH}_{2}\right)_{4} \mathrm{CH}=\mathrm{CHCH} \\
{ }_{7} \mathrm{COOCH}=\mathrm{CH}(\mathrm{CH}\end{array}$ \\
\hline $\mathrm{C} 18: 3$ & Linolenic & 18 & $\begin{array}{r}\mathrm{CH}_{3} \mathrm{CH}{ }_{2} \mathrm{CH}=\mathrm{CHCH}_{2} \mathrm{CH}=\mathrm{CHCH} \\
{ }_{2} \mathrm{CH}=\mathrm{CH}\left(\mathrm{CH}_{2}\right)_{7} \mathrm{COOH}\end{array}$ \\
\hline
\end{tabular}

${ }^{(1)}$ : As reported in Grabosky et al. (1998).

The fatty esters in biodiesel must be liquid at operating temperatures, and high melting points FAE may lead to problems on the fuel injector system. Therefore, long saturated FAE (such as the esters of C18:0 up to C24:0), which have high melting points, should be avoided. A technique called winterization may be used to avoid such problems, since it consists on removing solids formed during cooling of the oil esters (Knothe, 2005).

\section{Methods for estimation of critical properties}

In order to predict other physicochemical properties, critical temperature $\left(\mathrm{T}_{\mathrm{c}}\right.$, in $\left.\mathrm{K}\right)$, pressure $\left(\mathrm{P}_{\mathrm{c}}\right.$, in bars) and volume $\left(\mathrm{V}_{\mathrm{c}}\right.$, in $\left.\mathrm{cm}^{3} / \mathrm{mol}\right)$ are needed. Many methods are available, and most of them consist on group contribution methods. Reid et al. (1987) and Poling et al. (2000) describe and analyze these methods. Yuan et al. (2003) suggest the combined use of two methods: Ambrose's method and Joback's modification of Lydersen's method (Reid et al., 1987).

Ambrose's method consists on the use of the following equations to determine the critical properties. The normal boiling point $\left(\mathrm{T}_{\mathrm{b}}\right.$, in $\left.\mathrm{K}\right)$ and the molecular weight $(\mathrm{M})$ of the pure component are shown in Table 1. 


$$
\begin{gathered}
\mathrm{T}_{\mathrm{c}}=\mathrm{T}_{\mathrm{b}}\left[1+\left(1.242+\sum \Delta_{\mathrm{T}}\right)^{-1}\right] \\
\mathrm{P}_{\mathrm{c}}=\mathrm{M}\left(0.339+\sum \Delta_{\mathrm{P}}\right)^{-2} \\
\mathrm{~V}_{\mathrm{c}}=40+\sum \Delta_{\mathrm{V}}
\end{gathered}
$$

where $\Delta_{\mathrm{T}}, \Delta_{\mathrm{P}}$ and $\Delta_{\mathrm{V}}$ are constants given in Table 2-1 in Reid et al. (1987).

Joback modification of Lyndersen's method is similar to Ambrose's method. It also uses the following three equations and constants based on group contribution. The $\Delta_{\mathrm{T}}, \Delta_{\mathrm{P}}$ and $\Delta_{\mathrm{V}}$ constants for this method are given in Table 2-2 in Reid et al. (1987). Instead of the molecular weight, Joback uses the number of atoms $\left(\mathrm{n}_{\mathrm{A}}\right)$ to predict the critical pressure.

$$
\begin{gathered}
\mathrm{T}_{\mathrm{c}}=\mathrm{T}_{\mathrm{b}}\left[0.584+0.965 \sum \Delta_{\mathrm{T}}-\left(\sum \Delta_{\mathrm{T}}\right)^{2}\right]^{-1} \\
\mathrm{P}_{\mathrm{c}}=\left(0.113+0.0032 \mathrm{n}_{\mathrm{A}}-\sum \Delta_{\mathrm{P}}\right)^{-2} \\
\mathrm{~V}_{\mathrm{c}}=17.5+\sum \Delta_{\mathrm{V}}
\end{gathered}
$$

According to a comparison with over 400 compounds, Reid et al. (1987) concluded that Ambrose's method is more precise for the estimation of both critical temperature and pressure, while Joback's modification showed better results for the critical pressure. For this reason, the most accurate method will be used in each case.

Other useful property of the neat FAE is the acentric factor ( $\omega$, adimentional), which helps prediction other properties. According to Poling et al. (2000), the best way to predict $\omega$ is using the following equations.

$$
\begin{aligned}
& \omega=\frac{-\ln \left(\mathrm{P}_{\mathrm{c}} / 1.01325\right)+\mathrm{f}^{(0)}\left(\mathrm{T}_{\mathrm{br}}\right)}{\mathrm{f}^{(1)}\left(\mathrm{T}_{\mathrm{br}}\right)} \\
& \frac{-5.97616 \tau+1.29874 \tau^{1.5}-0.60394 \tau^{2.5}-1.06841 \tau^{5}}{\mathrm{f}_{\mathrm{br}}} \\
& \left.\mathrm{f}_{\mathrm{br}}\right)= \\
& \frac{-5.03365 \tau+1.11505 \tau^{1.5}-5.41217 \tau^{2.5}-7.46628 \tau^{5}}{\mathrm{~T}_{\mathrm{rr}}}
\end{aligned}
$$

where $T_{b r}=T_{b} / T_{c}$ and $\tau=1-T_{b r}$, with all the properties corresponding to the pure components.

Having the critical properties and the acentric factor, next step consists on employing mixing rules to define the pseudo-critical properties of the mixture (noted here as $\mathrm{T}_{\mathrm{cm}}, \mathrm{P}_{\mathrm{cm}}$ and $\mathrm{V}_{\mathrm{cm}}$ ). Lee-Kesler's equations [Eqs. (10) - (15)] are given in Table 4-3 Reid et al. (1987). In these equations, Lee-Kesler proposes the use of a binary interaction coefficient, $\mathrm{k}^{\prime}{ }_{\mathrm{ij}}$. In their recent work Yuan et al. (2003) simplified this coefficient to the unit, based on the fact that there is no published data available.

$$
\begin{aligned}
\mathrm{T}_{\mathrm{cm}} & =\frac{1}{\mathrm{~V}_{\mathrm{cm}}^{1 / 4}} \sum_{\mathrm{i}} \sum_{\mathrm{j}} \mathrm{y}_{\mathrm{i}} \mathrm{y}_{\mathrm{j}} \mathrm{V}_{\mathrm{cij}}^{1 / 4} \mathrm{~T}_{\mathrm{cij}} \\
\mathrm{V}_{\mathrm{cm}} & =\sum_{\mathrm{i}} \sum_{\mathrm{j}} \mathrm{y}_{\mathrm{i}} \mathrm{y}_{\mathrm{j}} \mathrm{V}_{\mathrm{cij}} \\
\omega_{\mathrm{cm}} & =\sum_{\mathrm{i}} \mathrm{y}_{\mathrm{i}} \omega_{\mathrm{i}} \\
\mathrm{T}_{\mathrm{cij}} & =\left(\mathrm{T}_{\mathrm{ci}} \mathrm{T}_{\mathrm{cj}}\right)^{1 / 2} \mathrm{k}_{\mathrm{ij}}^{\prime} \\
\mathrm{V}_{\mathrm{cij}} & =\frac{1}{8}\left(\mathrm{~V}_{\mathrm{ci}}^{1 / 3}+\mathrm{V}_{\mathrm{cj}}^{1 / 3}\right)^{3} \\
\mathrm{P}_{\mathrm{cm}}= & \left(0.2905-0.085 \omega_{\mathrm{m}}\right) \mathrm{RT}_{\mathrm{cm}} / \mathrm{V}_{\mathrm{cm}}
\end{aligned}
$$

where the subscript $\mathrm{m}$ refers to the mixture, the subscripts $i$ and $j$ refers to the neat components and $y$ are the molar fraction of the pure components. $\mathrm{R}$ is the gas constant $\left(\mathrm{R}=83.144\right.$ bar. $\left.\mathrm{cm}^{3} /(\mathrm{mol} . \mathrm{K})\right)$.

\section{Estimation of the density of the fuel}

The density of fuel components is one of the main properties, since it affects several other physical properties and it's directly related to ignition quality and heat of combustion which are extremely important for combustion. Density can be estimated by the use of the relation described by Yuan et al. (2003), which is based on the Raquett equation modified by Spencer and Danner (Reid et al. (1987). This method requires the value of density $\left(\rho_{R}\right.$ in $\left.\mathrm{kg} / \mathrm{l}\right)$ at a reference temperature, which can be easily obtained for the individual FAE.

$$
\begin{gathered}
\rho=\frac{\rho_{\mathrm{R}}}{Z_{\mathrm{RA}}^{\phi}} \\
Z_{\mathrm{RA}}=0.29056-0.08775 \omega \\
\phi=\left(1-\mathrm{T}_{\mathrm{r}}\right)^{2 / 7}-\left(1-\mathrm{T}_{\mathrm{r}-\mathrm{R}}\right)^{2 / 7}
\end{gathered}
$$

where $T_{r}$ is the reduced temperature $\left(T / T_{c}\right)$ and $T_{r-R}$ is the reduced temperature at the reference temperature 
and $\omega$ is the acentric factor of the individual FAE, as calculated above.

To estimate the density of the mixture, no consecrated method was found. Since all the components of biodiesel have the same nature, it was assumed that for density, a arithmetic combining rule could be used, such as described in Poling et al. (2000).

$$
\rho_{\mathrm{m}}=\sum_{\mathrm{i}} \mathrm{y}_{\mathrm{i}} \rho_{\mathrm{i}}
$$

\section{Estimation of the vapor pressure}

During injection, the fuel must vaporize before start burning. Vapor pressure is thus an important property. It is the pressure exerted by the vapor in equilibrium the vapor in equilibrium with the liquid phase, and it represents the volatility of the fuel. Poling et al. (2000) recommend that the vapor pressure $\left(\mathrm{P}_{\mathrm{vpr}}\right.$, in bars) should be estimated using the following relation, which is part of the AmbroseWalton corresponding stats method.

$$
\ln \mathrm{P}_{\mathrm{vpr}}=\mathrm{f}^{(0)}\left(\mathrm{T}_{\mathrm{r}}\right)+\omega \mathrm{f}^{(1)}\left(\mathrm{T}_{\mathrm{r}}\right)+\omega^{2} \mathrm{f}^{(2)}\left(\mathrm{T}_{\mathrm{r}}\right)
$$

where $\mathrm{f}^{(0)}$ and $\mathrm{f}^{(1)}$ may be calculated by the Eqs. (8) and (9), with the difference that here $T_{r}\left(T / T_{c}\right)$ must be used instead of the $T_{b r}$, and with $\tau=1-T_{r}$. The value of $\mathrm{f}^{(2)}$ should be calculated with the following equation.

$$
\begin{aligned}
& \mathrm{f}^{(2)}\left(\mathrm{T}_{\mathrm{r}}\right)= \\
& \frac{-0.064771 \tau+2.41539 \tau^{1.5}-4.26979 \tau^{2.5}+3.25259 \tau^{5}}{\mathrm{~T}_{\mathrm{r}}}
\end{aligned}
$$

\section{Viscosity of the fuel components}

Last, but not least important, is the viscosity of the fuel. High viscosity is the main reason why vegetable oils are not being used substituting conventional diesel fuel. Recently, Ceriani et al. (2007) have reported a new method for dynamic viscosity $(\eta)$ estimation, which is very useful at low temperatures. This method consists of a group contribution method with a perturbation term and a correction term, and it was developed and optimized to work with fatty compounds. The equation following equation may thus be used for the estimation of the viscosity of the neat fatty acid esters.

$$
\begin{gathered}
\ln \eta_{\mathrm{i}}=\sum_{\mathrm{k}} \mathrm{N}_{\mathrm{k}}\left(\mathrm{A}_{1 \mathrm{k}}+\frac{\mathrm{B}_{1 \mathrm{k}}}{\mathrm{T}}-\mathrm{C}_{1 \mathrm{k}} \ln \mathrm{T}-\mathrm{D}_{1 \mathrm{k}} \mathrm{T}\right)+ \\
{\left[\mathrm{M}_{\mathrm{i}} \sum_{\mathrm{k}} \mathrm{N}_{\mathrm{k}}\left(\mathrm{A}_{2 \mathrm{k}}+\frac{\mathrm{B}_{2 \mathrm{k}}}{\mathrm{T}}-\mathrm{C}_{2 \mathrm{k}} \ln \mathrm{T}-\mathrm{D}_{2 \mathrm{k}} \mathrm{T}\right)\right]+\mathrm{Q}}
\end{gathered}
$$

where the constants $A_{1 k}, B_{1 k}, C_{1 k}, D_{1 k}, A_{2 k}, B_{2 k}, C_{2 k}$ and $\mathrm{D}_{2 \mathrm{k}}$ are parameters obtained by Ceriani et al. (2007) from the regression of experimental data, $T$ is the absolute temperature, $\mathrm{k}$ represents each group in the molecule $\left(\mathrm{CH}_{3}, \mathrm{CH}_{2}, \mathrm{CH}=\right.$ and $\left.\mathrm{COO}\right), \mathrm{M}_{\mathrm{i}}$ is the molecular weight of the molecule and $Q$ is the correction term, dependent on temperature and the molecular structure, given by the following relations.

$$
\begin{gathered}
\mathrm{Q}=\varepsilon_{1} \mathrm{q}+\varepsilon_{2} \\
\mathrm{q}=-0.3157+\frac{9.324}{\mathrm{~T}}+0.054 \ln \mathrm{T}-0.00007812 \mathrm{~T} \\
\varepsilon_{1}=-5291.2+354 \mathrm{~N}_{\mathrm{c}} \\
\varepsilon_{2}=0.1984-0.0512 \mathrm{~N}_{\mathrm{cs}}
\end{gathered}
$$

where $\mathrm{q}$ is a function of the temperature $\mathrm{T}$ optimized based on the experimental data used by Ceriani et al. (2007), $N_{c}$ is the total number of carbons in the molecule of the FAE and $\mathrm{N}_{\mathrm{cs}}$ is the number of carbon atoms in the alcoholic part of the molecule ( 1 for methyl esters, 2 for ethyl esters, etc.).

With viscosity of each FAE calculated, it's then possible to estimate the viscosity of the mixture. Allen et al. (1999b), proposed a mixing rule that uses the mass fraction of the FAEs $\left(\mathrm{w}_{\mathrm{i}}\right)$ and the viscosity of each component. More precise relations were reported, as the Grunberg-Nissan equation, described by Yuan et al. (2009), which is considerably more complex. Therefore, for a first estimation the following equation is appropriated.

$$
\ln \eta_{\mathrm{m}}=\sum_{\mathrm{i}} \mathrm{w}_{\mathrm{i}} \ln \eta_{\mathrm{i}}
$$

In their work, Allen et al. (1999b) also describe equations for the estimate viscosity at $40^{\circ} \mathrm{C}$ for saturated FAME and FAEE from 8 to 18 carbon atoms, and for the unsaturated FAE with 18 carbons. These equations may be used to evaluate the precision of the results of Eq. (23), but they do not explain the variation of viscosity with the temperature.

\section{Estimation of other useful properties}

As many authors have shown, with the properties described in this work it is possible to estimate 
almost every other property that affects the fuel atomization and the combustion process. The surface tension, for example, can be estimated by the Macleod-Sugden method (Reid et al., 1987; Allen et al., 1999a), and depends on the liquid density, critical temperature and boiling point.

Cetane number $(\mathrm{CH})$, that is a measure of the ignition quality of a fuel, depends on the properties described. It is not possible to estimate the $\mathrm{CH}$ directly from these properties, but studies have tried to estimate the $\mathrm{C \#}$ with the regression of experimental data. Freedman (1990) and Klopfenstein (1982) have reported such possibility, the first with the use of physical properties that can be estimated with the equations showed in the present work and the second based only on the carbon number and the number of double bonds on the fatty acid chain. The greatest problem with such methods is that they are limited by the results available on the literature, which are sparse for FAEE and unsaturated esters in general. As a basic rule the $\mathrm{C \#}$ of a fuel increases with increasing chain length and decreases with increasing unsaturation (Knothe, 2005).

\section{RESULTS AND DISCUSSION}

The methods chosen for the estimation of the FAE properties need some basic information. This information is presented in Table 2, for the main fatty acid ethyl esters (FAEE) found in natural oils.

Table 2. Basic information needed for the estimative of other properties. Data from SCIFINDER $\mathbb{R}$ Database.

\begin{tabular}{|c|c|c|c|c|}
\hline $\begin{array}{c}\text { Shorthand } \\
\text { name }\end{array}$ & $\begin{array}{c}\text { FAEE } \\
\text { Name }\end{array}$ & $\begin{array}{c}\text { Normal } \\
\text { Boiling } \\
\text { point } \mathrm{T}_{\mathrm{b}}(\mathrm{1}) \\
\left({ }^{\circ} \mathrm{C}\right)\end{array}$ & $\begin{array}{c}\text { Liquid } \\
\text { density } \rho^{(2)} \\
(\mathrm{kg} / \mathrm{l})\end{array}$ & $\begin{array}{c}\text { Molecular } \\
\text { Weight } \\
M(\mathrm{~g} / \mathrm{mol})\end{array}$ \\
\hline Et 12:0 & $\begin{array}{c}\text { Ethyl } \\
\text { Laurate }\end{array}$ & 269.0 & 0.867 & 228.371 \\
\hline Et 14:0 & $\begin{array}{c}\text { Ethyl } \\
\text { Myristate }\end{array}$ & 295.0 & 0.865 & 256.424 \\
\hline Et 16:0 & $\begin{array}{c}\text { Ethyl } \\
\text { Palmitate }\end{array}$ & 342.2 & 0.864 & 284.477 \\
\hline Et 18:0 & $\begin{array}{c}\text { Ethyl } \\
\text { Stearate }\end{array}$ & 356.0 & 0.862 & 312.538 \\
\hline Et 18:1 & $\begin{array}{c}\text { Ethyl } \\
\text { Palmitoleat } \\
\mathrm{e}\end{array}$ & 355.50 & 0.875 & 282.460 \\
\hline Et 18:2 & $\begin{array}{c}\text { Ethyl } \\
\text { Ethyl }\end{array}$ & 385.90 & 0.842 & 310.515 \\
\hline Et 18:3 & $\begin{array}{c}\text { Ethyl } \\
\text { Linolenate }\end{array}$ & 388.30 & 0.882 & 308.499 \\
\hline
\end{tabular}

(1): Measured at $1 \mathrm{~atm}$.

(2): Measured at $20^{\circ} \mathrm{C} 1 \mathrm{~atm}$.

First, the predictions were made on the individual FAEE, in temperatures between $280 \mathrm{~K}$ and the critical temperature of the components. Then, it was possible to estimate the fuel properties for different fatty acid profiles simulating different feedstocks, and thus different fuels.

The estimation methods were first tested with the FAME, and compared with the results presented by Yuan et al.(2003). The results confirmed that the algorithm used agrees with the previous results, with small differences due to the choice of methods. The acentric factor estimation method is different, and some of the mixing rules as well. However, the same trends were observed.

\section{Calculated properties of individual FAEE}

Based on the Eqs. (2), (3), (7) and (8), the critical properties and the acentric factors were calculated for the FAEE listed on Table 2. These results are presented in Table 3. Comparing these results to those reported by Yuan et al. (2003), which studied the FAME, it can be observed that a ethyl ester follow the same trends that methyl esters, in what concerns the relation between carbon number, unsaturation and critical properties. The values change mostly because of the increase of $\mathrm{T}_{b}$ for the FAEE, and the change on the number of $\mathrm{CH}_{2}$ that alters the value of group contribution constants for both Ambrose and Joback's methods.

Table 3. Estimated values for the critical properties and the acentric factors of the neat FAEE.

\begin{tabular}{|c|c|c|c|c|c|c|c|c|}
\hline $\begin{array}{c}\text { Short- } \\
\text { hand } \\
\text { name }\end{array}$ & $\begin{array}{c}\mathrm{Et} \\
12: 0\end{array}$ & $\begin{array}{c}\mathrm{Et} \\
14: 0\end{array}$ & $\begin{array}{c}\mathrm{Et} \\
16: 0\end{array}$ & $\begin{array}{c}\mathrm{Et} \\
18: 0\end{array}$ & $\begin{array}{c}\mathrm{Et} \\
16: 1\end{array}$ & $\begin{array}{c}\mathrm{Et} \\
18: 1\end{array}$ & $\begin{array}{c}\mathrm{Et} \\
18: 2\end{array}$ & $\begin{array}{c}\mathrm{Et} \\
18: 3\end{array}$ \\
\hline$T c(\mathrm{~K})$ & 696.87 & 718.45 & 767.06 & 774.38 & 785.58 & 812.96 & 817.75 & 802.39 \\
\hline$P c(\mathrm{bars})$ & 14.47 & 13.10 & 11.96 & 11.01 & 12.20 & 11.21 & 11.41 & 11.63 \\
\hline $\begin{array}{c}V c \\
\left(\mathrm{~cm}^{3} / \mathrm{mol}\right)\end{array}$ & 845.5 & 957.5 & 1069.5 & 1181.5 & 1049.5 & 1161.5 & 1141.5 & 1121.5 \\
\hline$\omega(-)$ & 0.7632 & 0.837 & 0.9072 & 0.9738 & 0.8978 & 0.965 & 0.956 & 0.9469 \\
\hline
\end{tabular}

With the results present on Table 3 , and with the value of the densities presented in Table 1, it was possible to estimate the densities of the individual FAEE. These results are presented in Fig. 1(a). It should be noticed the experimental density found for Ethyl Oleate is low compared with both the saturated and unsaturated FAEE, what results in a curb slightly displaced towards lower densities. However, the results are in agreement with the trend reported by Yuan et al. (2003) and Liew (1992).

These results agree very well with data reported for saturated FAEE, by Liew (1992), and the difference is less than $1 \%$. There is no data to compare the unsaturated FAEE, but the method used should be valid for both, because the estimation is based on the group contribution methods that take in count the double bonds.

Using the Eq. (20), it was possible to describe the behavior of the components in what concerns their vapor pressure. As shown in Fig. 2(b), the vapor pressure is very low for low temperatures and starts to rise at the boiling point. No published measurements were found, but the data follow the same trend describe in Yuan et al. (2003), with the difference being caused by the different boiling point 
of the FAME used in that work. In Fig. 2(b), it's also possible to observe that the vapor pressure increases with increasing carbon number and with the number of double bonds.

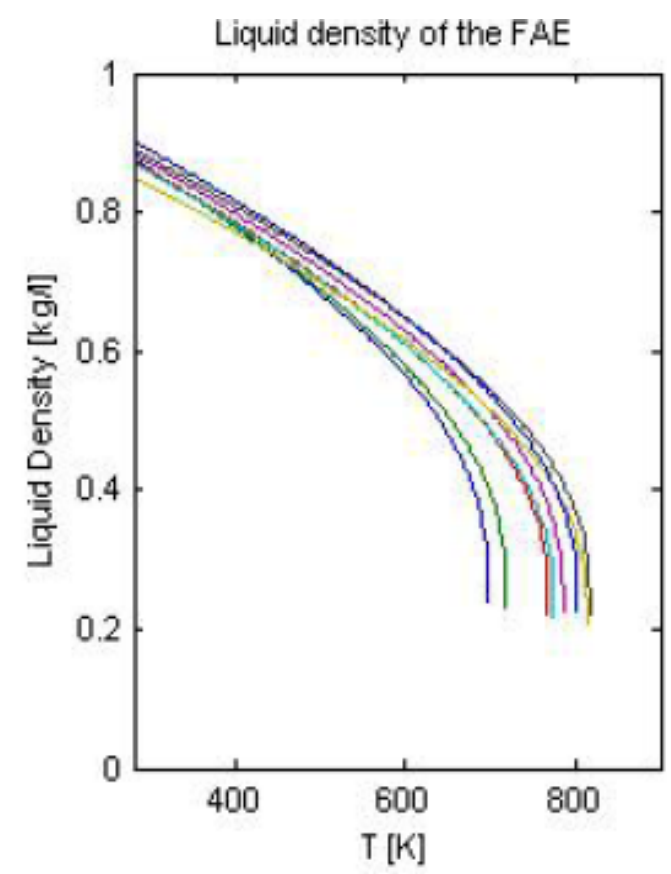

(a)

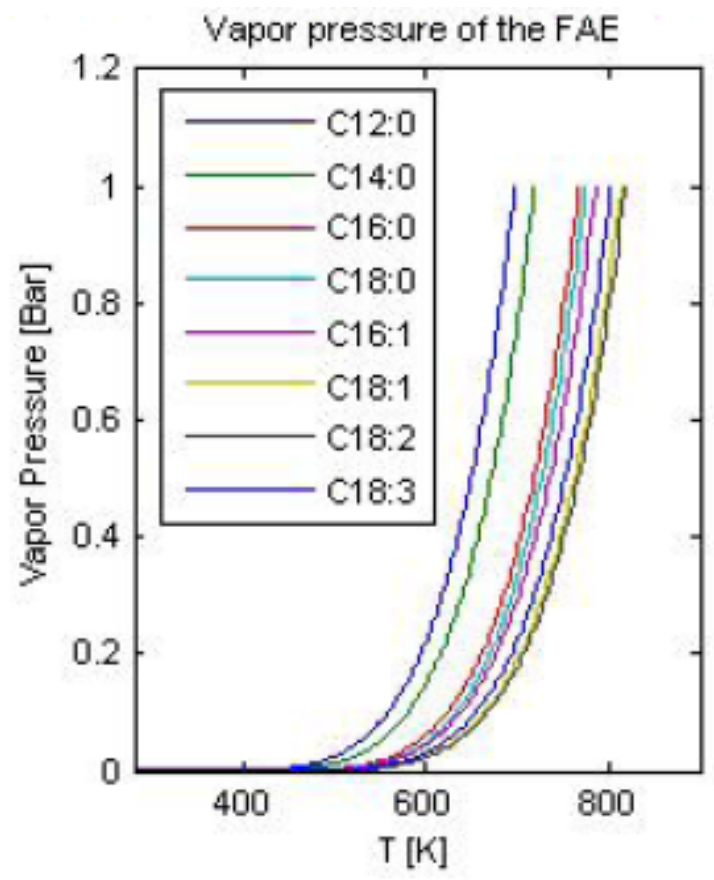

(b)

Figure 2. (a) Liquid densities and (b) Vapor pressure of neat FAEE.

For the estimation of the liquid viscosities of the components, Eqs. 2526 were used, resulting in the behavior show in Fig. 3. These results are hard to confirm, since in literature there is no much data of dynamic viscosity for FAEE. The viscosity observed follow the same trend describe in Yuan et al. (2003), with increasing viscosity with increasing chain length and reduction of it with increasing insaturation.

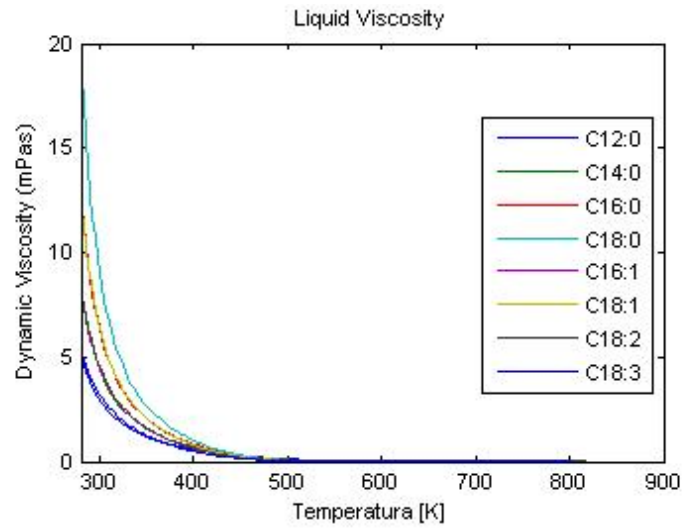

Figure 3. Liquid Viscosity of neat FAEE.

When comparing the results with those presented by Allen et al. (1999b), at $40^{\circ} \mathrm{C}$, the estimated values deviate considerably. Table 4 contains the results of this comparison.

Table 4. Difference estimated and reported (Allen et al., 1999b) values of dynamic viscosity.

\begin{tabular}{|c|c|c|c|c|c|c|c|c|}
\hline $\begin{array}{c}\text { Shorthand } \\
\text { name }\end{array}$ & $\begin{array}{c}\text { Et } \\
12: 0\end{array}$ & $\begin{array}{c}\text { Et } \\
14: 0\end{array}$ & $\begin{array}{c}\text { Et } \\
16: 0\end{array}$ & $\begin{array}{c}\text { Et } \\
18: 0\end{array}$ & $\begin{array}{c}\text { Et } \\
16: 1\end{array}$ & $\begin{array}{c}\text { Et } \\
18: 1\end{array}$ & $\begin{array}{c}\text { Et } \\
18: 2\end{array}$ & $\begin{array}{c}\text { Et } \\
18: 3\end{array}$ \\
\hline $\begin{array}{c}\text { Estimated } \\
\text { visco sity } \\
\text { (mP a.s) }\end{array}$ & 2.27 & 3.18 & 4.43 & 6.13 & 3.24 & 4.52 & 3.33 & 2.45 \\
\hline $\begin{array}{c}\text { Allen et al. } \\
\text { (1999) } \\
\text { (mPa.s) }\end{array}$ & 2.30 & 3.14 & 4.16 & 5.50 & - & 3.88 & 3.23 & 2.87 \\
\hline Deviation & $-1 \%$ & $1 \%$ & $7 \%$ & $11 \%$ & - & $17 \%$ & $3 \%$ & $-15 \%$ \\
\hline
\end{tabular}

These results show some large deviations between estimated and reported results on long chain FAEE (C16-C18). However, even on experimental data, deviations of up to $7 \%$ were reported (Allen et al. 1999b). Other authors have reported larger deviations concerning viscosity of fatty esters (Yuan et al., 2003). Thus, since the experimental data of fatty acid ethyl esters is sparse, it's still important to apply the method, and these estimates may be considered acceptable for initial estimations.

\section{Results of the mixing rules}

In order to demonstrate the potential of the estimation methods described, five different "synthetic" oil compositions were designed, based on the literature, considering the following feedstocks: soy, palm, canola and two microalgae, as given in Table 5. Only the main fatty acids where take in count for the matter of simplifications. 
Table 5. Composition of "synthetic fuels", based on the literature. The values are referent to the mass fraction.

\begin{tabular}{|c|c|c|c|c|c|c|c|c|c|c|}
\hline & $\begin{array}{c}\mathrm{Et} \\
12: 0\end{array}$ & $\begin{array}{c}\mathrm{Et} \\
14: 0\end{array}$ & $\begin{array}{c}\mathrm{Et} \\
16: 0\end{array}$ & $\begin{array}{c}\mathrm{Et} \\
18: 0\end{array}$ & $\begin{array}{c}\mathrm{Et} \\
16: 1\end{array}$ & $\begin{array}{c}\mathrm{Et} \\
18: 1\end{array}$ & $\begin{array}{c}\mathrm{Et} \\
18: 2\end{array}$ & $\begin{array}{c}\mathrm{Et} \\
18: 3\end{array}$ & $\mathrm{UFAE}^{(4)}$ & $\mathrm{PUFAE}^{(5)}$ \\
\hline Soy $^{(1)}$ & $0 \%$ & $0 \%$ & $6 \%$ & $2 \%$ & $1 \%$ & $61 \%$ & $20 \%$ & $10 \%$ & $92 \%$ & $30 \%$ \\
\hline $\begin{array}{c}\text { Canola } \\
(1)\end{array}$ & $0 \%$ & $0 \%$ & $4 \%$ & $2 \%$ & $0 \%$ & $57 \%$ & $22 \%$ & $16 \%$ & $94 \%$ & $37 \%$ \\
\hline Palm $^{(1)}$ & $0 \%$ & $12 \%$ & $43 \%$ & $4 \%$ & $0 \%$ & $34 \%$ & $7 \%$ & $0 \%$ & $41 \%$ & $7 \%$ \\
\hline $\begin{array}{c}\text { Micro- } \\
\text { algae } \\
1^{(2)}\end{array}$ & $0 \%$ & $0 \%$ & $40 \%$ & $4 \%$ & $10 \%$ & $24 \%$ & $15 \%$ & $7 \%$ & $55 \%$ & $21 \%$ \\
\hline $\begin{array}{c}\text { Micro- } \\
\text { algae } \\
2^{(3)}\end{array}$ & $0 \%$ & $11 \%$ & $31 \%$ & $1 \%$ & $52 \%$ & $5 \%$ & $0 \%$ & $0 \%$ & $57 \%$ & $0 \%$ \\
\hline
\end{tabular}

(1) From Tab. 4 in Yuan et al. (2009), only considering the FAE with 12 to 18 carbons.

(2) Scenedesmus obliquus, microalgae oil, as reported by Morais (2008), considering C12-C18.

(3) Phaeodactlylum tricornutum microalgae oil, as reported by Tonon et al. (2002), considering C12C18.

(4) UFAE and PUFAE are the mass fractions of unsaturated fatty acids and poly-unsaturated fatty acids esters.

With the compositions given by Table 5 , it was possible to use the Lee-Kesler mixing rules (Reid et al., 1987) to calculate the critical properties of the mixture. Equation (12) was used to calculate the acentric factor. The vapor pressures, the densities and the dynamic viscosity of the mixture were then estimated, based on the methods described above.

For these three properties, both Soy and Canola mixes present very close results. They both present a high percentage of unsaturated fatty acids in their profile $(92 \%$ and $94 \%)$ and the highest percentage of Linoleic acid (20\% and 22\%).

The tested Palm and microalgae ester presented high amounts of the ethyl palmitate $(43 \%, 40 \%$ and $31 \%$ ), which has a relatively low boiling point $\left(342^{\circ} \mathrm{C}\right)$. This contributes to the displacement of the vapor pressure curb and the density towards lower temperatures (Fig. 4(a)). The lowest the vapor pressure at a given temperature, smaller the amount of fuel vaporized at that temperature. The atomization and vaporization process depend on this parameter, and very low vapor pressures lead to difficulties in ignition, especially in cold weathers. Ignition problem lead to higher amounts of unburned fuel and incomplete combustion, which affects the emissions of $\mathrm{CO}, \mathrm{HC}$ and PM. Volatile compounds in the fuel, such as small chain fatty esters, tend to reduce the initial boiling point of the mixture, and may have a significant impact on these emissions.

Fuel consumption is one of the biggest issues of the actual engine development. The volumetric fuel consumption, which is more usual to the normal costumer, depends basically on the heat capacity of a fuel and its density. Having volumetric fuel consumption competitive with conventional diesel is a desirable quality. However, as shown in figure, the density of the fuel at low temperature don't vary much (Fig. 4(b)), and it's smaller than conventional diesel. Once again, Soy and Canola present similar values, while palm has the lower densities (at high temperature) and microalgae between both groups.

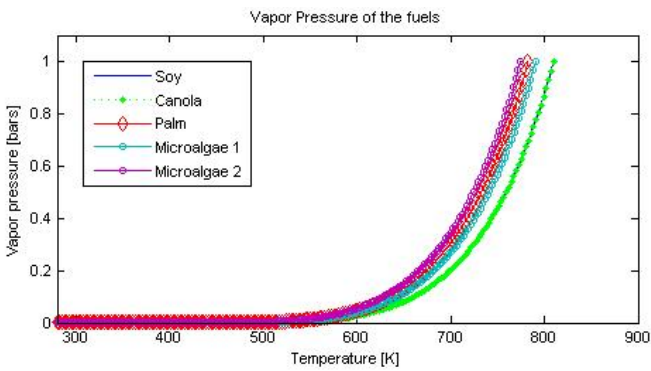

(a)

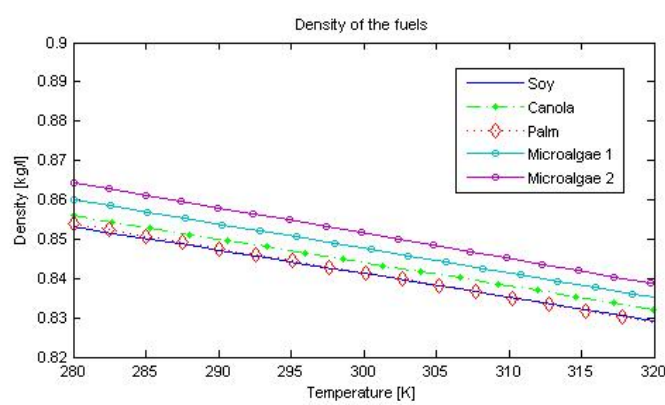

(b)

Figure 4. (a) Vapor pressure and (b) Densities of the fuels

The viscosity of the fuels are presented in Fig. 5. Palm presented the highest viscosity, mostly because it presents the lowest amount of UFAE and PUFAE of the fuels analysed. Yuan et al. (2009), reported higher viscosity for Palm methyl ester (3.87 mPa.s) than for Soy or Canola (3.67 and $3.7 \mathrm{mPa} . \mathrm{s}$ ), which is partially in agreement with these results, since the canola ester presented lower viscosity than soy ester. It's important to consider that, as show in Tab. 4, the viscosity is overestimated for both ethyl palmitate (Et 16:0) and ethyl oleate (Et 18:1), which are important components of all the fuels analysed, leading to an overestimation of fuel viscosity.

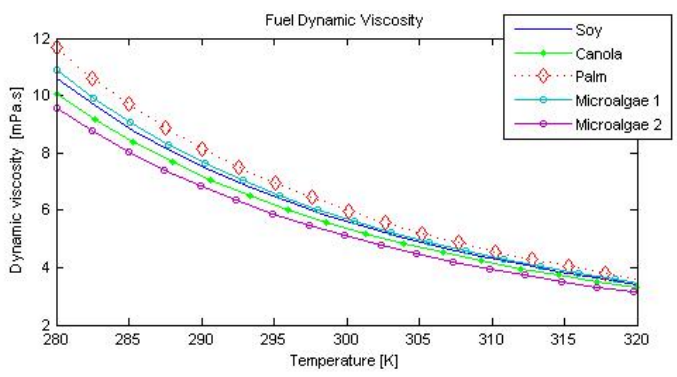

Figure 5. Dynamic viscosity of the fuels.

The fuel viscosity is an important factor of the atomization process. Higher viscosities could lead to 
an increase in spray tip penetration and the decrease of spray cone angle while using Biodiesel. The increased spray tip penetration lead to an increase in pollutant emissions, especially PM (Graboski, 1998). The kinematic viscosity $(v=\eta / \rho)$ is normally included in biodiesel standards, and thus it must be controlled. The viscosity increases with the carbon number of the fatty acid, so long chains should be avoided (C18:0, C20:0), as reported by Knothe (2005).

Other characteristics should be also considered in the characterization of new feedstock. Cold flow properties (cloud point, pour point, cold-filter plugging point) are limiting characteristics since they affect directly the engine operation. These characteristics depend on the melting point of individual FAE. As a basic rule, the longer the fatty acid chain higher is its melting point and worst are the cold flow properties. Saturated esters over C16 have high melting points and tend to crystallize at cold temperatures, what lead to flow problems on the injection systems.

Knothe (2005) also reports that the oxidative stability depends on the number of double bonds of the fatty acid, since the double bonds are susceptible to reaction with oxygen, and PUFAE are much more sensitive than monounsaturated fatty esters. The susceptibility of a Soy or Canola ester is therefore much higher than that of Palm oil. This is an important characteristic, since the degradation of biodiesel impacts the combustion process and the pollutant emission.

The most important FAE are those described in this work. However, in some feedstock, such as coconut oil, small saturated chains may be found; these have low cetane numbers, and poor ignition quality, what limits their use. Other sources of oil, present really long fatty acids, such as C20:0 or C24. In this case, the cold flow properties are problematic, since these FAE have high melting points. The intermediary compounds, ranging from $\mathrm{C} 10: 0$ to C18:0 for the saturated FAE, are suited for biodiesel production. The unsaturated FAE from $\mathrm{C} 16$ to $\mathrm{C} 20$ are also suited for biodiesel production, but the $\mathrm{CN}$ might be a problem, since it decreases with increasing unsaturation.

\section{CONCLUSIONS}

Several methods for estimating the properties of biodiesel components are available. The application of these methods, combined with mixing rules and experimental data may allow the estimation of the most important physicochemical properties of this alternative fuel. This may be performed even before the production of biodiesel, and at very low cost. Thus, estimation of the fuel properties is a viable and useful step on the use of a new feedstock for biodiesel production and to emission studies.

The methods used were accurate enough, for a first estimative. Viscosity estimation should be refined. Since the method applied is very complex, the deviation may be affected by an error. Other method, based on experimental data might perform better in such estimations.

The simulation of microalgae biodiesel allowed a better understanding of the potential of this feedstock. Since the "synthetic" algae oil had high amounts of oleic acid and palmitic acid, their esters presented properties that were intermediary between Soy/Canola and Palm oil ethyl esters, and might performe very well. Microalgae cultive also allow a better control on the fatty acid profil, which is especially important for fuel optimization.

Many fuel properties affect directly the engine performance and pollutant emissions, what makes the importance of knowing and optimizing the fuel composition clear. Even if many plants or microorganisms may produce oils, not necessarily the biodiesel produced from it have the quality necessary for the operation of modern engines. With the improvement in biodiesel production, it may be possible to produce high quality fuel that complies with the standards and helps limiting the pollutant emission and substituting conventional diesel.

\section{ACKNOWLEDGEMENTS}

The authors thank the financial support to this research provided by the Brazilian National Council of Scientific \& Technological Development, CNPq, through solicitations 39/2007 and 26/2008.

\section{REFERENCES}

Allen, C. A. W., Watts, K. C., Ackman, R. G., and Pegg, M. J., 1999a, Predicting the surface tension of biodiesel fuels from their fatty acid ester composition, JAOCS, Vol. 76, pp. 317-323.

Allen, C. A. W., Watts, K. C., Ackman, R. G., and Pegg, M. J., 1999b, Predicting the viscosity of biodiesel fuels from their fatty acid ester composition, Fuel, Vol. 78, pp. 1319-1326.

Ceriani, R., Gonçalves, C., Rabelo, J., Caruso, M., Cunha, A. C. C, Cavaleri, F. W., Batista, E. A. C., and Meirelles, A. J. A., 2007, Group contribuition model for predicting viscosity of fatty compounds, Journal of Chemistry Engineering Data, Vol. 52, pp. 965-972.

Chisti, Y., 2007, Biodiesel from microalgae, Biotechnology Advances, Vol.25, pp. 294-306, doi:10.1016/j.biotechadv.2007.02.001.

Dzida, M., and Prusakiewiecz, 2008, The effect of temperature and pressure on the physicochemical properties of petroleum diesel oil and biodiesel fuel, Fuel, Vol. 87 (10-11), pp. 1941-1948, doi:10.1016/j.fuel.2007.10.010.

Freedman, B., and Bagby, M. O., 1990, Predicting Cetane Numbers of n-alcohols and Methyl Esters from their Physical Properties, JAOCS, Vol. 67, No. 9, pp. 565-571. 
Graboski, M. S., McCormick, R. L., 1998, Combustion of fat and vegetable oil derived fuels in diesel engines, Progress in Energy and Combustion Science, Vol. 24, No. 2, pp.125-164, doi:10.1016/S0360-1285(97)00034-8.

Knothe, G., 2005, Dependence of biodiesel fuel properties on the structure of fatty acid alkyl esters, Fuel Processing Technology, Vol. 86, No. 10, pp. 1059-1070, doi:10.1016/j.fuproc.2004.11.002.

Knothe, G., 2008. Designer Biodiesel. Optimizing Fatty Ester Composition to Improve Fuel Properties, Energy and Fuels, Vol. 22, pp.1358-1364, doi:10.1021/ef700639e.

Klopfenstein, W. E., 1982, Estimation of Cetane Index for esters of fatty acid. JOACS. Vol. 59, No. 12, pp. 531-533.

Lapuerta, M., Armas, O., and RodríguezFernandes, J., 2008, Effect of biodiesel fuel on diesel engine emissions, Progress in Energy and Combustion Science, Vol. 34, pp. 198-223, doi:10.1016/j.pecs.2007.07.001.

Liew. K. Y., and Seng. C. E., (1992) Molal Volumes of Some n-Fatty Acids and Their Methyl and Ethyl Esters, JAOCS, Vol. 69, No. 8, pp. 734740.

Meng, X., Yang, J., Xu, X., Zhang, L., Nie, Q., and Xian, M., 2009, Biodiesel production from oleaginous microorganisms, Renewable Energy, Vol. 34, pp. 1-5, doi:10.1016/j.renene.2008.04.014.

Morais, M. G., Costa J. A. V., 2008, Fatty acids profile of microalgae cultived with carbon dioxide, Ciênc. Agrotec., Vol. 32, No. 4, pp. 1245-1251.

Poling, B. E., Prausnitz, J. C., and O'Connel, J. P., 2000, The Properties of Gases and Liquids, 5th Edition, McGraw-Hill, ISBN 0-07-011682-2.

Reid, R. C., Prausnitz, J. C., and Poling, B. E., 1987, The Properties of Gases and Liquids, 4th Edition, McGraw-Hill, ISBN 0-07-051799-1.

Song, D., Fu. J., and Shi. D., 2008, Exploitation of Oil-bearing Microalgae for biodiesel, Chinese Journal of Biotechnology, Vol. 24, No. 3, pp. 341348, doi:10.1016/S1872-2075(08)60016-3.

Tonon, T., Harvey, D., Larson, T. R., and Graham, I. A., 2002, Long chain polyunsaturated fatty acid production and particioning to triacylglycerols in four microalgae, Phytochemestry, Vol. 61, pp. 15-24.

Yuan. W., Hansen. A. C., and Zhang. Q., 2003, Predicting the physical properties of biodiesel for combustion modeling, Transactions of the ASAE, Vol. 46, No. 6, pp. 1487-1493.

Yuan, W., Hansen, A. C., and Zhang, Q., 2009, Predicting the temperature dependent viscosity of biodiesel fuels, Fuel, Vol. 88, pp. 1120-1126, doi:10.1016/j.fuel.2008.11.011. 